\title{
A METHOD AND A STATION FOR MEASUREMENT OF THE AERODYNAMIC PROPERTIES OF CROP SEEDS
}

\author{
L. Gierz", D. Wojcieszak ${ }^{* *}$, J. Szymenderski ${ }^{* * *}, \dot{Z}$. Staszak ${ }^{*}$, J. Marcinkiewicz*
}

\begin{abstract}
In order to construct sowing and transporting elements in modern pneumatic seed drills it is necessary to know the aerodynamic properties of crop seeds. They are characterised by three indicators: terminal velocity, drag coefficient and fineness ratio. The aim of the study was to present a method and a research station for measurement of the aerodynamic properties of crop seeds in vertical and horizontal planes. The method assumes measurement of geometric properties of seeds by neuron image analysis and aerodynamic measurements in a specially designed station.
\end{abstract}

Keywords: aerodynamic properties, terminal velocity, two planes of measurements, seeds

\section{Introduction}

Pneumatic seed drills equipped with a central seed distribution system and pneumatic hoses transporting seeds directly into coulters are the most efficient machines for sowing cereals. The knowledge of aerodynamic properties of crop seeds is particularly important for designing heads separating a stream of seeds and positioning sensors detecting obstructions in the hoses through which seeds are transported in an airstream (two-phase gas-body flow) directly into coulters. The morphological and anatomical structure as well as physical properties of crop seeds are considerably diversified. Therefore, it is necessary to investigate the physical properties of crop seeds.

When a seed is placed freely in an airstream, it moves in it as a result of gravity and the aerodynamic force. The value and direction of the aerodynamic force depend on micro - and macrogeometric characteristics of the seed surface, seed orientation in an airstream as well as airstream velocity and flow direction. Apart from the geometric characteristics, aerodynamic properties are the second most important physical properties of crop seeds. They are characterised by the following three indicators:

- terminal velocity,

- drag coefficient,

- fineness ratio.

Terminal velocity seems to reflect the aerodynamic properties of seed mixtures best of the three indicators listed above. The drag coefficient depends exclusively on the seed shape and surface, whereas the fineness ratio depends only on the seed dimensions and weight. Terminal velocity is decisive to the parameters of the airstream in which seeds will be transported (Feder, 1990).

Assist. Prof.Łukasz Gierz, PhD.: Poznań University of Technology, ul. Piotrowo 3, 60-965 Poznan, Poland, Institute of Machines and Motor Vehicles (lukasz.gierz@put.poznan.pl)

** Assist. Prof.DawidWojcieszak, PhD.: Poznań University of Life Sciences, ul. WojskaPolskiego 28 , 60-637 Poznań, Poland, Institute of Biosystem Engineering (dawid.wojcieszak@up.poznan.pl)

*** Assist. Prof. Jan Szymenderski, PhD.: Poznań University of Technology, ul. Piotrowo 3a, 60-965 Poznań, Poland, Department of Electrical Engineering, (jan.szymenderski@put.poznan.pl)

* Assist. Prof. Żaneta Staszak, PhD.: Poznań University of Technology, ul. Piotrowo 3, 60-965 Poznan, Poland, Institute of Machines and Motor Vehicles (zaneta.staszak@put.poznan.pl)

* $\quad$ M.Sc., eng. Jacek Marcinkiewicz, Poznań University of Technology, ul. Piotrowo 3, 60-965 Poznan, Poland, Institute of Machines and Motor Vehicles (jacek.marcinkiewicz@put.poznan.pl) 
There are two methods of measuring terminal velocity. The first is the free fall method, where the fluid (air) remains still, whereas seeds fall freely. However, the long trajectory is a disadvantage of the method (Shellard \& Mcmillan, 1978). Measurement stations need to be very tall. Measurements of the terminal velocity of cereal seeds with this method require heights exceeding $35 \mathrm{~m}$. The other method is usually called the suspension method. It is based on the dependence of the balance of gravity and the drag force. In this method, the particle remains at rest, while the fluid (air) is set in motion. The moment of the balance of the forces indicates suspension of the particle in the airstream whose velocity corresponds to the terminal velocity of the particle. The measurement station described in this article is based on this method.

The aim of the study is to present a method and a concept of a station for measurement of the aerodynamic properties of crop seeds in vertical and horizontal planes. Most crop seeds are ellipsoidal rather than regularly round-shaped. During pneumatic transport in mechanical pneumatic seed drills seeds may move vertically, horizontally or they may tumble. Therefore, it is necessary to acquire basic aerodynamic properties of seeds, especially their terminal velocity in vertical and horizontal positions to make a computer simulation of their transport.

\section{Methods}

\subsection{Measurement of geometric properties}

For a long time the shape and dimensions of seeds have been measured to construct machinery, especially sowing machines. Earlier methods based on classic tools of linear measurements were laborious but not very efficient. Due to the continuous improvement of methods of computation and simulation of processes taking place in machines, such as the sowing process, it is necessary to provide information about the dimensions and shape of seeds. It is also necessary to measure basic dimensions of seeds to determine their aerodynamic properties. At this stage we assumed that the photogrammetric method would be used for measuring the dimensions and shape of seeds. Original software based on the photogrammetric method was designed at the Department of Working Machines, Poznan University of Technology, Poland to measure the dimensions and shape of seeds. Detailed photographs of a group of seeds placed on backlit plates were binarised, segmented and subjected to geometrical calculations, which consisted in determining the dimensions of seed outlines. The results of these measurements were statistically processed. Alternatively, images can be analysed using neuronal networks and computer software to model seeds for calculations with the finite element method (FEM). For many years researchers from the Poznań University of Life Science have been developing computer software which generates an FEM mesh from a series of photographs of seed cross-sections made with a microtome (Wereset al., 2009). The geometric properties of crop seeds can be determined by means of neuronal image analysis, which is commonly used to determine the parameters and properties of agricultural products (Koszela et al., 2015, Wojcieszak et al., 2015, Zaborowicz et al., 2016).

\subsection{Aerodynamic properties}

Apart from geometric properties, aerodynamic properties are also significant to the process of pneumatic transport of seed mixtures, especially the transport of sowing material in the installations of mechanical pneumatic seed drills. Terminal velocity, drag coefficient and fineness ratio are basic indicators of the aerodynamic properties of the seeds of cereals and other crops. Terminal velocity is the velocity at which a particle remains apparently suspended in an airstream (Kram, 2010). It characterises the airstream generated by a fan (in this study - an industrial vacuum cleaner). Terminal velocity best reflects the aerodynamic properties of seeds and it is often used as a distinguishing feature. The drag coefficient characterises interdependences between the stream of a fluid (air) and a solid particle (seed) placed in it. The fineness ratio characterises the capacity of seeds to resist the airstream flowing at a particular velocity. It chiefly depends on the seed dimensions and weight as well as the shape and type of the seed surface. It is necessary to stress the fact that there is evidence that the aerodynamic properties of seeds are also influenced by their moisture (Gupta et al., 2007). 


\subsection{Station for measurement of aerodynamic properties}

The construction of a research station was prepared for this study. It is an air channel which enables measurement of terminal velocity in vertical and horizontal planes - see Figure 1.

The design of the station for measurement of the aerodynamic properties of seeds was based on the following assumptions:

- measurements were based on the suspension method,

- measurements range from 1 to $25 \mathrm{~m} \cdot \mathrm{s}^{-1}$.

The basic element of the station is a fan in the form of an industrial vacuum cleaner (1), which forces airflow. Its main element is a glass pipe of $100 \mathrm{~mm}$ in diameter with seed guides inside. Figure 1, Detail A shows the measurement channel magnified three times. The guides are marked in red. Position (11) shows how to place seeds vertically and horizontally in the guides. There are four guides in the station. After verification of geometric parameters selected seeds is drilled - one along the longitudinal axis, the other - along the transverse axis (see Figure 1, Position 11). The guides (5) are made from nylon lines of $0.15 \mathrm{~mm}$ in diameter in order to eliminate unnecessary flow disorders. The airflow is regulated by means of an inverter, which enables change of the revolutions of the rotor of the industrial vacuum cleaner. Apart from that, the station is equipped with a strangler (10) which enables additional regulation of the airflow. A levelling insert (9) will equalise the airflow profile and eliminate further measurement disturbances. It is a honeycomb or a sieve insert. Another element of the station is the measurement section. It is composed of a Prandtl tube (KIMO) (3) connected by flexible cables with a Magnesense II pressure transducer, model MS-W102 (7), with an accuracy of $1-2 \%$. It is connected to a computer (8) by means of a MeRedlab USB measurement interface (Mailhaus) (6). The pressure transducer (9) and measurement interface enable continuous collection of data on differences in total and static pressure. The results can be recorded in a text file. Each measurement of terminal velocity will be replicated 10 times in order to minimise errors. There is another opening below the Prandtl tube for entering seeds into the measurement channel. Four seeds at a time will be entered through the opening and placed on the guides (5). When the opening is closed tight, the measurement procedure begins.
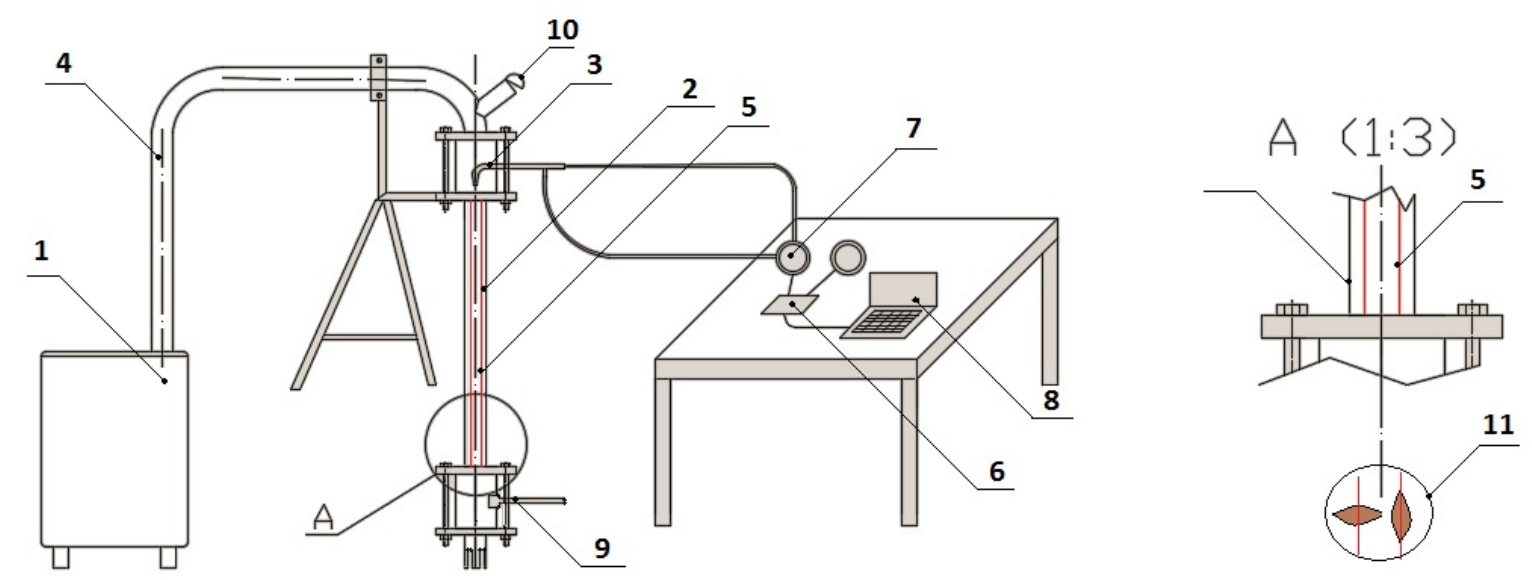

Fig. 1: A schematic diagram of the station for measurements of seed terminal velocity in two planes: $1-$ industrial vacuum cleaner, 2 - glass channel, 3 - Prandtl tube, 4 -vacuum cleaner suction tube, 5 - grain direction guides, 6 - USB measuring interface, 7 - pressure transducer, 8 -computer, 9 - insert for velocity profile equalisation, 10 - strangler, 11 - seed adjustment directions.

The terminal velocity can be calculated indirectly by measuring the difference between the total and static pressure, i.e. the dynamic pressure in the channel constructed for this purpose. When we convert the basic formula $P_{d}=\frac{\rho \cdot V_{k}^{2}}{2}$, we can calculate the terminal velocity as follows:(1)

$$
V_{k}=\sqrt{\frac{2 \cdot P_{d}}{\rho}}\left[m \cdot s^{-1}\right]
$$


where:

$\mathrm{P}_{\mathrm{d}}$ - dynamic pressure $[\mathrm{Pa}]$,

$\rho$ - fluid (air) density $\left[\mathrm{kg} \mathrm{m}^{-3}\right]$

\section{Summary}

The concept of the research station for indirect measurement of terminal velocity and the method described above were prepared in order to implement the research project Lider VIII, which is managed and executed by the authors of this study. The guides will enable indirect measurement of terminal velocity of seeds moving vertically and horizontally. The results of measurements can be used for further simulation investigations of the movement of seeds.

\section{Acknowledgement}

The research was financed by the National Centre for Research and Development under the LIDER VIII project No. LIDER/24/0137/L-8/16/NCBIR/2017.

\section{References}

Feder St. (1990) Metoda i stanowisko badawcze do określania prędkości krytycznej ziarna, Zeszyty Naukowe Politechniki Poznańskiej, seria Maszyny Robocze i Pojazdy, Poznań, 1990, nr 35, s. 47-52.

Gupta R.K., Arora G., Sharma R. (2007) Aerodynamic properties of sunflower seed. J. Food Eng., 79 (2007), pp. 899-904

Koszela K., Raba B.,Zaborowicz M., Przybyl K., Wojcieszak D., Czekala W., Ludwiczak A., Przybylak A., Boniecki P. Przybyl J. (2015) Computer Image Analysis in Caryopses Quality Evaluation as Exemplified by Malting Barley. Proc. SPIE 9631, Seventh International Conference on Digital Image Processing (ICDIP 2015), 96310V (6 July 2015); doi: 10.1117/12.2197032

Kram B. B. (2010) Właściwości aerodynamiczne nasion soi. Inżynieria Rolnicza. Kraków, 2010 1(119), s 265-271.

Shellard J. E., Mcmillan R. H., (1978) Aerodynamic properties of threshed wheat materials. Journal of Agricultural Engineering Research, 23, 273-281.

Weres J., Olek W., Kujawa S. (2009) Comparison of optimization algorithms for inverse FEA of heat and mass transport in biomaterials. Journal of Theoretical and Applied Mechanics, 2009, 47(3), 701-716

Wojcieszak D., Przybył J., Lewicki A., Ludwiczak A., Przybylak A., Boniecki P., Koszela, Zaborowicz M., Przybył K., Witaszek K. (2015) Use of neural image analysis methods in the process to determine the dry matter content in the compost. Proc. SPIE 9631, Seventh International Conference on Digital Image Processing (ICDIP 2015), 963118 (6 July 2015); doi: 10.1117/12.2197035

Zaborowicz M., Wojcieszak D., Górna K., Kujawa S., Kozłowski R.J., Przybył K., Mioduszewska N., Idziaszek P., Boniecki P. (2016) Determination of dry matter content in composted material based on digital images of compost taken under mixed visible and UV-A light. Proc. SPIE 10033, Eighth International Conference on Digital Image Processing (ICDIP 2016), 100332G (August 29, 2016); doi: 10.1117/12.2243985. 